\title{
Produtividade e qualidade da forragemde trigo-mourisco (Fagopyrum esculentum Moench) e de milheto (Pennisetum glaucum (L.) R.BR)
}

\author{
Productivity and forage quality of buckwheat ("Fagopyrum esculentum" Moench) and \\ pearl millet ("Pennisetum glaucum" (L.) R.BR)
}

\author{
GÖRGEN, Angela Valentini ${ }^{1}$; CABRAL FILHO, Sergio Lucio Salomon ${ }^{2 *}$; LEITE, \\ Gilberto Gonçalves ${ }^{2}$; SPEHAR, Carlos Roberto ${ }^{2}$; DIOGO, José Mauro da Silva²; \\ FERREIRA, Daniel Barcelos ${ }^{1}$
}

\begin{abstract}
${ }^{1}$ Universidade de Brasília, Brasília, Distrito Federal, Brasil.
${ }^{2}$ Universidade de Brasília, Faculdade de Agronomia e Medicina Veterinária, Brasília, Distrito Federal, Brasil.

*Endereço para correspondência: slcabral@unb.br
\end{abstract}

\section{RESUMO}

Objetivou-se com este trabalho comparar o valor forrageiro do milheto e trigo-mourisco, sob irrigação, em diferentes idades de corte. Utilizouse delineamento experimental em blocos ao acaso, com os tratamentos arranjados em modelo de parcelas subdivididas. As plantas foram cultivadas durante a estação seca, sob irrigação e colhidas em três idades de corte, 47, 57 e 67 dias (tratamentos). Foram determinados os teores de matéria seca (MS), proteína bruta (PB), fibra em detergente neutro (FDN), fibra em detergente ácido (FDA), matéria mineral e produção de gases in vitro e a produção de matéria seca. A produção do trigo-mourisco (2301, 3144 e $4471 \mathrm{~kg} \mathrm{MS} / \mathrm{ha})$ foi superior à do milheto $(437,592$ e $2224 \mathrm{~kg}$ MS/ha) nas três idades de corte. Os teores de PB do milheto foram, em média, $22,3 \%$ nas três idades de corte, mas no trigo-mourisco reduziu de $23,8 \%$ no primeiro corte, para $14 \%$ nos demais cortes. O trigo mourisco apresentou maior teor de FDN no primeiro corte $57,6 \%$ contra $52,1 \%$ do milheto, entretanto diminuiu no segundo e terceiro cortes, $46,8 \%$ e $41,2 \%$, respectivamente, enquanto que no milheto mantiveram-se em $55,1 \%$ e $52,7 \%$ no segundo e terceiro corte. Os teores de FDA forma mais elevados para o trigo mourisco em comparação com o milheto nas três idades de corte estudadas. A produção de gases foi maior para o trigo mourisco em comparação ao milheto, com exceção do primeiro corte, quando o trigo apresentou maiores taxas de fermentação. $\mathrm{O}$ trigo mourisco apresentou qualidade como forrageira, sendo mais produtivo e nutritivo do que o milheto durante o período seco, sob irrigação.

Palavras-chave: fermentação in vitro, qualidade de forragem, trigo-sarraceno

\section{SUMMARY}

This trial compared forage production and quality of Pearl Millet and Buckwheat in three cutting age on irrigation conditions during dry season, evaluated in a randomized block split plot design with tree replications. Was determined content of Dry Matter (DM), Crude Protein (CP), Neutral Detergent Fiber (NDF), Acid Detergent Fiber $(\mathrm{ADF})$, Mineral Matter (MM) and in vitro gas production. Forage production of Buckwheat was higher than Pearl Millet in all the cutting ages. Pearl Millet CP content was similar to all three cuts but Buckwheat $\mathrm{CP}$ content was higher in the first cut and reduced in the others. The NDF content of Buckwheat was higher in the first cut and reduced in the others, meanwhile Pearl Millet presented low NDF value in the first cut but increased in the second and third cut. The Buckwheat presented high ADF content than Pearl Millet in all the cuts. In vitro gas production from Pearl Millet was higher in the first cut but more high for Buckwheat in the second and third cuts. Buckwheat produced more forage with high quality than Pearl Millet during dry season.

Keywords: forage quality, in vitro fermentation, buckwheat 


\section{INTRODUÇÃO}

$\mathrm{Na}$ estação de seca o crescimento das plantas forrageiras tende a ser reduzido, forçando os produtores a lançarem mão de algumas estratégias para minimizar os efeitos da baixa produtividade. Entre elas, uma opção interessante é a utilização de espécies ou cultivares de ciclo curto e resistentes, inclusive, ao clima seco e frio.

O trigo mourisco, sarraceno ou trigopreto é uma planta poligonácea oriunda das regiões centrais da Ásia. Tem sido cultivado em maior escala no Paraná, visando a produção de grãos e a fabricação de farinha, mas também é exportado para o Japão e países europeus. É uma planta rústica, de ciclo curto, de múltiplos usos e tem sido redescoberto em vários países devido ao seu potencial como alimento nutracêutico, dietético e medicinal (FAO, 2011).

O trigo-mourisco pode ser utilizado como planta sucessora de culturas de grão como soja, milho e sorgo, devido a sua capacidade de se desenvolver bem em vários tipos de solo. Apesar de seus grãos serem muito utilizados na alimentação animal, a parte aérea da planta também pode ser utilizada na forma de feno e silagem para ruminantes (FERREIRA et al., 1983), pois seu valor nutritivo se assemelha ao das gramíneas (SILVA et al., 2002). A parte aérea do trigo mourisco (Fagopyrum esculentum Moench, Poligonaceae) pode ser utilizado como forragem a partir dos 30 dias de idade, até o início do seu florescimento, aos 60 dias, pois apresenta produtividade satisfatórias em condições de baixa pluviosidade.

O milheto (Pennisetum glaucum (L.) R. BR.) é uma gramínea originária da África. É uma forrageira anual de verão, bem adaptada a diferentes tipos de solos e pode produzir até 60 toneladas de massa verde e 20 toneladas de matéria seca por hectare, quando cultivado no início da primavera (KICHEL et al., 2000). Sua forragem apresenta alto valor nutritivo $(24 \%$ de proteína bruta), boa aceitabilidade e digestibilidade (60\% a $78 \%)$.

A informação sobre a qualidade nutricional dessas plantas é de interesse de agricultores e pecuaristas na intenção de utiliza-las para a alimentação de seus rebanhos. As técnicas in vitro de produção de gases são capazes de simular o ambiente ruminal e a digestão enzimática (THEODOROU et al., 1994) e baseiam-se na estimativa do volume de gases produzidos e conversão de volume a partir de dados de pressão (MAURÍCIO et al., 2003).

Deste modo, realizou-se este trabalho objetivando avaliar o rendimento forrageiro e a qualidade nutricional da parte aérea do trigo mourisco a partir dos 30 dias de idade, até o florescimento, bem como comparar com a forragem de milheto.

\section{MATERIAL E MÉTODOS}

O trabalho foi desenvolvido no período de junho a setembro de 2011, em solo do tipo Latossolo Vermelho-Amarelo distrófico, típico da região do Distrito Federal. A temperatura média durante o período experimental variou de 14 a $19^{\circ} \mathrm{C}$.

$\mathrm{O}$ delineamento experimental foi em blocos ao acaso, no qual os tratamentos foram arranjados em modelo de parcela subdividida, em que as espécies consistiram a parcela principal, e as idades de corte nas subparcelas.

As idades de corte foram 47, 57 e 67 dias, época em que o trigo mourisco 
ainda não produziu grão, podendo ser utilizado como forrageira. As parcelas tiveram a dimensão de $(5 \times 4 \mathrm{~m})$. O plantio foi realizado em sulcos espaçados de $50 \mathrm{~cm}$ entre linhas. A adubação de plantio constou de 550 $\mathrm{kg} / \mathrm{ha}$ de uma mistura de fertilizantes (500kg de 04-30-16 e 50Kg de FTE BR-10). A área experimental foi irrigada por sistema de aspersão durante o período experimental. Aos 34 dias pós germinação foi aplicada uma adubação nitrogenada em cobertura, na dosagem de $80 \mathrm{~kg}$ de N/ha na forma de uréia.

Após as colheitas, as amostras foram secas à $65^{\circ} \mathrm{C}$, moídas e analisadas quanto aos teores de matéria seca (MS), proteína bruta $(\mathrm{PB})$, fibra em detergente neutro (FDN) fibra em detergente ácido (FDA) e matéria mineral (MM). As amostras também foram submetidas ao processo de fermentação ruminal in vitro para a determinação da produção de gases.

Os teores de MS, cinzas, PB e FDA foram determinados segundo a AOAC (2012). A determinação dos teores de FDN foi realizada segundo o método descrito por Van Soest et al. (1991). A produção de gases in vitro das amostras foi obtida utilizando a metodologia de Theodorou et al. (1994), modificada por Mauricio et al. (1999), usando um transdutor de pressão. As medições das produções de gases foram realizadas nos horários: 3, 6, 9, 12, 16, 24, 36, $48 \mathrm{e}$ 72 horas após incubação.

O inóculo foi colhido de dois bovinos fistulados mantidos em pasto de Brachiaria brizantha cv. Maradu e suplementados com $10 \mathrm{~kg}$ de silagem de milho e $2 \mathrm{~kg}$ de concentrado por dia. Os animais foram mantidos em jejum de 12 horas antes da colheita do inóculo. Amostras do conteúdo ruminal composta por material sólido e líquido foram retiradas de dois animais $\mathrm{e}$ misturadas, formando uma amostra composta.

O inóculo foi filtrado em camada dupla de pano de algodão e mantido em banho maria a $39^{\circ} \mathrm{C}$ em fluxo de $\mathrm{CO}_{2}$ até a inoculação. Foram inoculados $10 \mathrm{ml}$ do líquido ruminal em frascos de vidro de $160 \mathrm{ml}$ contendo $1 \mathrm{~g}$ de substrato e $90 \mathrm{ml}$ de solução nutritiva tamponante. Após a inoculação os frascos foram tampados com rolhas de borrachas e lacrados, posteriormente, foram incubados em estufa com circulação de ar a $39^{\circ} \mathrm{C}$.

Os valores obtidos foram analisados pelo programa SAS (2002), versão 9.0, procedimento GLM, e o teste de média adotado foi o de Tukey ao nível de 5\%.

\section{RESULTADOS E DISCUSSÃO}

Os resultados de produção apresentaram médias diferentes $(\mathrm{P}<0,05)$ entre os tratamentos, sendo que a produção do trigo mourisco foi superior do que a do milheto (Figura 1). As elevações contínuas em produtividade do trigo mourisco nas idades de corte avaliadas mostram maior adaptabilidade dessa espécie vegetal às condições climáticas do inverno. Entretanto, o milheto somente apresentou produtividade satisfatória na última idade de corte, no início da primavera, quando as condições climáticas foram favoráveis ao crescimento e desenvolvimento das plantas por causa da elevação da temperatura, tendo em vista ser essa espécie uma cultura típica de verão. Menezes \& Leandro (2004) trabalhando com trigo mourisco também encontraram produtividade inferior a $4.000 \mathrm{~kg} \mathrm{MN} / \mathrm{ha}$. 


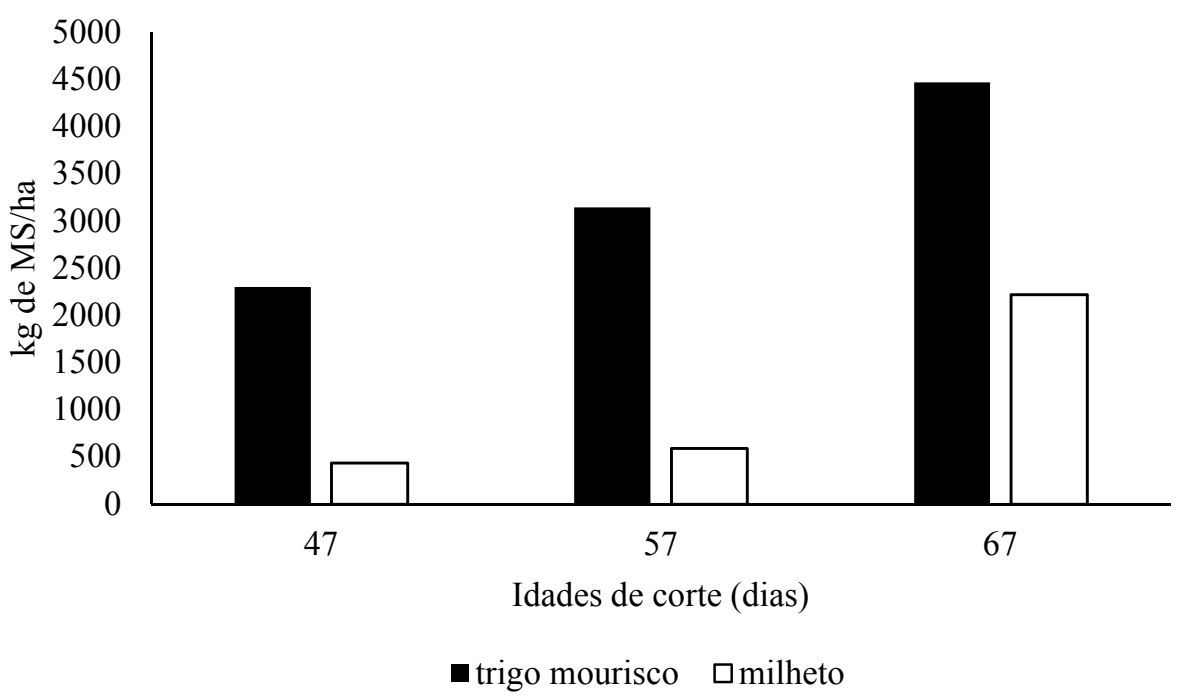

Figura 1. Produtividade de forragem de trigo mourisco e milheto avaliado em três idades de crescimento

Os teores de matéria seca (Tabela 1) do milheto foram superiores ao do trigo mourisco no primeiro e terceiro cortes. Entretanto, no primeiro corte o trigo mourisco não atingiu $10 \%$ de matéria seca do milheto, mostrando que sua forragem aos 47 dias possui alto conteúdo de água em sua composição.

Houve interação $(\mathrm{P}<0,05)$ no teor de proteína bruta $(\mathrm{PB})$ entre as espécies trigo mourisco e milheto (Tabela 2) e as idades de cortes. Na primeira idade de corte aos 47 dias, o teor de PB da forragem em ambas espécies foi semelhante.
Entretanto, nas idades de cortes aos 57 e 67 dias o trigo mourisco apresentou menor teor de PB em relação ao milheto. Provavelmente isso tenha sido em decorrência do trigo mourisco ter apresentado maior teor de fibra em detergente ácido (FDA) nessas duas idades de cortes. Além disso, a produção de gases também foi superior nessas duas idades de corte (Figura 2). Klein et al. (2010) e Fialho et al. (1982) também encontraram resultados semelhantes quando avaliaram variedades precoces de trigo mourisco.

Tabela 1. Teor de Matéria seca (MS\%), proteína bruta (PB\%), fibra em detergente neutro (FDN\%) e fibra em detergente ácido (FDA\%) de trigo mourisco e de milheto avaliados aos 47, 57 e 67 dias de crescimento

\begin{tabular}{lcccccc}
\hline \multirow{2}{*}{ Variáveis Avaliadas } & \multicolumn{3}{c}{ Trigo mourisco } & \multicolumn{3}{c}{ Milheto } \\
\cline { 2 - 6 } & 47 & 57 & 67 & 47 & 57 & 67 \\
\hline Matéria seca & 9,5 & 14,2 & 13,2 & 12,7 & 13,8 & 17,2 \\
Proteína bruta & $23,8^{\mathrm{Aa}}$ & $14,7^{\mathrm{Bb}}$ & $14,3^{\mathrm{Bb}}$ & $24,2^{\mathrm{Aa}}$ & $22,5^{\mathrm{Aab}}$ & $20,2^{\mathrm{Ab}}$ \\
Fibra em detergente neutro & $57,6^{\mathrm{Aa}}$ & $46,8^{\mathrm{Bb}}$ & $41,2^{\mathrm{Bc}}$ & $52,1^{\mathrm{Aa}}$ & $55,1^{\mathrm{Aa}}$ & $52,7^{\mathrm{Aa}}$ \\
Fibra em detergente ácido & $31,7^{\mathrm{Aa}}$ & $33,4^{\mathrm{Aa}}$ & $32,0^{\mathrm{Aa}}$ & $25,1^{\mathrm{Ba}}$ & $27,5^{\mathrm{Aa}}$ & $27,0^{\mathrm{Ba}}$ \\
Matéria mineral (Cinzas) & $15,2^{\mathrm{Aa}}$ & $10,1^{\mathrm{Bb}}$ & $11,4^{\mathrm{Ac}}$ & $12,1^{\mathrm{Ba}}$ & $11,4^{\mathrm{Aab}}$ & $10,6^{\mathrm{Bb}}$ \\
\hline
\end{tabular}

Letras maiúsculas na linha comparam resultados entre variedades dentro de cortes e letras minúsculas na linha comparam resultados entre cortes dentro das espécies. Teste de Tukey $(\mathrm{P}<0,05)$. 
O teor de proteína bruta do trigo mourisco e do milheto, foram maiores aos 47 dias de idade. Provavelmente, isso ocorreu porque nessa idade de corte a forragem das duas espécies estava com baixos teores de FDA e isso implica em baixos teores de fibra, o que favorece a elevação do teor proteico (MERTENS, 1994). As plantas de trigo mourisco quando ultrapassam a idade de 50 dias, apresentaram estiolamento com muitas hastes e alongamento do caule, produzindo muita folha e induzindo a elevação dos teores de fibras (GOMES et al., 2014). Avaliando variedades de milheto, Frizzo Filho (2004) também observou maior teor de PB na forragem desta espécie aos 45 dias. Do ponto de vista das exigências dos ruminantes e dos não ruminantes herbívoros em produção, a forragem do trigo mourisco $\mathrm{e}$ do milheto, aos 47 dias, apresentaram valores suficientes para atender à necessidade proteica dessas espécies.

Houve interação $(\mathrm{P}<0,05)$ quanto ao teor de FDN entre as espécies trigo mourisco e milheto e as idades de cortes avaliadas. $\mathrm{O}$ teor de FDN da forragem de ambas espécies aos 47 dias foi semelhante. Entretanto, aos 57 e 67 dias de idade, a forragem do trigo mourisco apresentou menor teor de FDN em relação a do milheto, contrastando com resultados encontrados por Klein (2010). Isso mostra que a forragem do milheto aumenta o teor de fibra em maior proporção do que a do trigo mourisco. Apesar das plantas de trigo mourisco com idade acima de 50 dias apresentarem estiolamento $\mathrm{e}$ alongamento do caule, seu teor de fibras permaneceu baixo.

Os teores de FDA de trigo mourisco e milheto, não apresentaram interação entre as idades de corte $(\mathrm{P}>0,05)$. $\mathrm{O}$ teor de FDA da forragem de milheto foi semelhante ao trigo mourisco aos 57 dias, sendo que aos 47 e 67 dias de idade, o trigo mourisco apresentou maiores teores de FDA $(\mathrm{P}<0,05)$. Contrastando com $\mathrm{o}$ teor de FDN, a forragem do trigo mourisco mostrou tendência de elevação no teor de FDA, provavelmente em decorrência de aspectos estruturais das plantas, tais como ramificações, porte, bem como do fortalecimento dos constituintes da parede celular no decorrer do envelhecimento das plantas. Resultados semelhantes, 32\% de FDA, também foram encontrados por Klein (2010).

Houve interação $(\mathrm{P}<0,05)$ entre espécies e idades de cortes de trigo mourisco e milheto para os teores de MM. Os teores de MM da forragem do trigo mourisco e do milheto foram maiores aos 47 dias de idade, mas semelhante nas demais idades avaliadas. Nesta idade, as plantas estão em pleno estádio vegetativo, com alto teor de PB e outros componentes nutricionais (FONTANELI et al., 2009). Segundo Moore (1994) o teor de MM mostra a riqueza da forragem em elementos macro e micronutrientes.

Os resultados de fermentação ruminal in vitro mostraram que houve diferença em termos de produção de gás, entre a forragem do trigo mourisco e do milheto (Figura 2). Também mostraram que não houve inibição de crescimento microbiano por algum fator nutricional presente no trigo mourisco.

O milheto produziu maior volume de gás na primeira idade de corte, enquanto $o$ trigo mourisco produziu menos. Ou seja, é provável que o milheto no início de seu desenvolvimento possua maior fermentabilidade em relação ao trigo mourisco. As análises bromatológica mostraram que houve diminuição da fração FDN do trigo mourisco com o avanço da idade, provavelmente pela emissão da inflorescência, melhorando o valor nutricional (GOMES et al., 2014). 

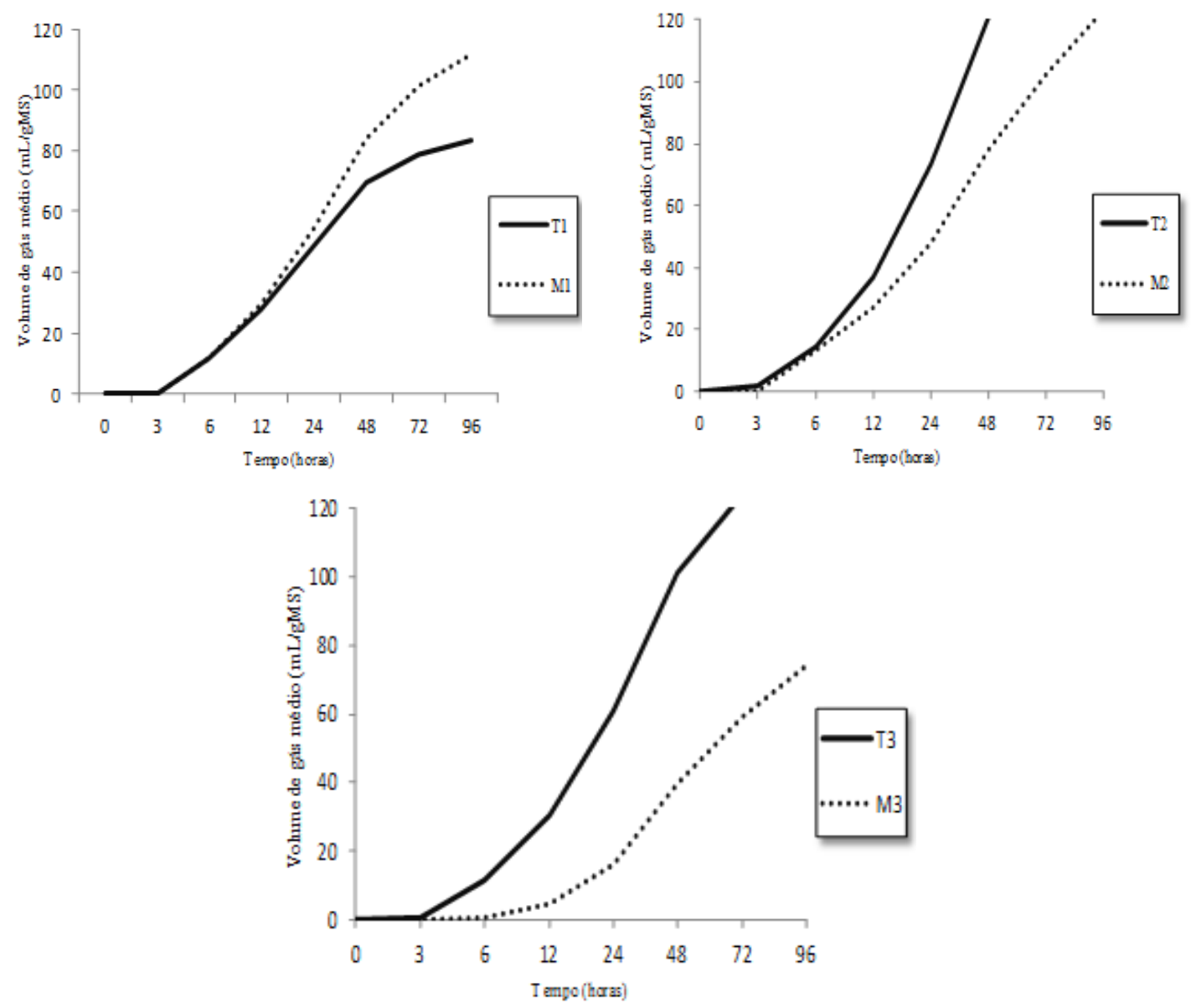

Figura 2. Curvas de fermentação da forragem de trigo mourisco (T1, T2 e T3) e de milheto (M1, M2 e M3) avaliadas, respectivamente aos 47, 57 e 68 dias de crescimento.

As curvas de produção de gases aos 57 dias mostraram que a fermentação ruminal das duas espécies foram diferentes nesse estágio de crescimento. A curva do milheto tendeu ao decréscimo de produção de gás ao longo do seu desenvolvimento, enquanto que a do trigo mourisco ao acréscimo. Ou seja, em termos de fatores ótimos para a digestão ruminal, o trigo mourisco apresentou melhor qualidade aos $57 \mathrm{e}$ 67 dias após o plantio, enquanto que o milheto foi melhor aos 47 e 57 dias.

Os dois tipos de forrageiras apresentaram resultados similares em relação ao comportamento ruminal aos 57 dias de crescimento. Isso provavelmente ocorreu por existir proporção semelhante de substrato disponível para digestão, notado pelos teores de FDN e FDA, pois a maioria dos gases é liberada pela fermentação dos carboidratos (NOGUEIRA et al., 2006). Forragem com maior conteúdo de carboidratos estruturais, com degradação mais lenta, pode aumentar a taxa de produção de gases, por causa da maior atuação da microbiota e enzimas durante a digestão (MERTENS 1994).

Aos 67 dias a produção de gases foi bem distinta, sendo que o volume de gases apresentado pelo trigo mourisco foi maior do que o do milheto. A produção de gases do trigo mourisco foi 
Rev. Bras. Saúde Prod. Anim., Salvador, v.17, n.4, p.599-607 out./dez., 2016 http://www.rbspa.ufba.br ISSN 15199940

semelhante a encontrada por Cabral Filho et al. (2005), para sorgo aos 60 dias de idade. Essa comparação mostra a proximidade do comportamento ruminal do trigo mourisco com uma forragem de comum utilização na alimentação animal.

A diminuição da produção de gases no milheto no segundo e terceiro corte podem indicar uma maior permanência do alimento no rúmen, o que provavelmente resultará em uma menor fermentação.

Nesse sentido, as maiores produções de gases observadas no trigo mourisco no segundo e terceiro cortes, inferem maior digestibilidade da forragem nessas idades, sendo que, para forragens mais fermentáveis, ou digestíveis a taxa de produção de gases deve ser mais alta e devem alcançar potencial máximo de fermentação em menos tempo.

A produção e qualidade da forragem de trigo mourisco cultivado no inverno, foi maior do que a do milheto, notadamente a partir dos 50 dias de crescimento, indicando que a forragem do mesmo pode ser utilizada para a alimentação de ruminantes nesta estação do ano.

\section{REFERÊNCIAS}

ASSOCIATION OF OFFICIAL ANALYTICAL CHEMISTS - AOAC. Official Methods of Analysis. 19a edition. U.S.A, 2012. 3000p.

CABRAL FILHO, S.L.S.; ABDALLA, A.L.; BUENO, I.C.S; NOZELLA, E.F.; RODRIGUES, J.A.S. Ruminal fermentation and degradability of sorghum cultivar whole crop, and grains, using an in vitro gas production technique. Animal Feed Science and Technology, v.123, n.1, p.329-339, 2005.
CAMPOS, F.P.; LANNA D.P.D.; BOSE, M.L.V., BOIN, C. Avaliação do sistema de monitoramento computadorizado de digestão "in vitro": 1. Testes preliminares. Revista da Sociedade Brasileira de Zootecnia, v.29, n.2, p.525-530, 2000.

FARIAS JUNIOR, W.G.; GONÇALVES, L.C.; MAURICIO, R.M.; RODRIGUES, J.A.S.; COLODO, J.C.N.; FARIA, W.G.; SOUZA, L.F. Avaliação das silagens de sorgo BRS610 em sete estágios de maturação pela técnica "in vitro" semi-automática de produção de gases. Arquivo Brasileiro de Medicina Veterinária e Zootecnia, v.62, n.4, p.898-905, 2010.

FAO. FAO Statisctical Yearbook. FAO Statistics Division. (2011). Disponível em: <www.faostst.fao.org $>$. Acesso em: 10 fev. 2013.

FERREIRA, A.S.; FIALHO, E.T.; GOMES, P.C.; FREITAS, A.R. Trigo Mourisco (Fagopyrum esculentum, Moench) na alimentação de suínos em terminação. Revista da Sociedade Brasileira de Zootecnia, v.12, n.1, p.132-142. 1983.

FIALHO, E.T; BELLAVER, C; GOMES, P.C.; ALBINO, L.F.T. Composição química e valores de digestibilidade dos ingredientes nacionais, utilizados em rações para suínos. Concordia, SC: Embrapa Suínos e Aves, 1982. 3p. (Comunicado Técnico, 33).

FRIZZO FILHO, O.; LEITE, G.G.; DIOGO, J.M.S.; RAMOS A.K.B. Produtividade e composição química de variedades de Milheto Pennisetum glaucum (L.) R. BR.) em diferentes idades de cortes visando a fenação. Pasturas Tropicales, v.28, n.3, p.46-54, 2006. 
Rev. Bras. Saúde Prod. Anim., Salvador, v.17, n.4, p.599-607 out./dez., 2016 http://www.rbspa.ufba.br ISSN 15199940

FONTANELI, R.S.; SANTOS, H.P.; NASCIMENTO JUNIOR, A.; MINELLA, E.; CAIERÃO, E.

Rendimento e valor nutritivo de cereais de inverno de duplo propósito: forragem verde e silagem ou grãos. Revista Brasileira de Zootecnia, v.38, n.111, p.2116-2120, 2009.

GOMES, R.B.; CABRAL FILHO, S.L.S.; LEITE, G.G.; OLIVEIRA, J.F.A. Forage Production and Quality of buckwheat (Fagopyrum esculentum Möench L.). In: REUNIÃO ANUAL DA SOCIEDADE BRASILEIRA DE ZOOTECNIA, 51., 2014, Aracajú. Anais... Aracajú: Sociedade Brasileira de Zootecnia. 2014.

KICHEL, A.N.; MIRANDA, C.H.B. Uso do Milheto como planta forrageira. Campo Grande, MS: Embrapa Gado de Corte, 2000. (Divulgação, 46).

KLEIN, V.A.; NAVARINI, L.L.; BASEGGIO, M.; MADALOSSO, T.; COSTA, L.O.Trigo mourisco: uma planta de triplo propósito e uma opção para rotação de culturas em áreas sob plantio direto. Revista Plantio Direto, 117.ed., 2010. Disponível em:

$<$ http://www.plantiodireto.com.br/?body= cont_int\&id=991> Acesso em: 6 out. 2012 .

MAURICIO, R.M.; PEREIRA, R.G.R.; GONÇALVES, L.C.; RODRIGUEZ, N.M. Relação entre pressão e volume para implantação da técnica "in vitro" semi-automática de produção de gases na avaliação de forrageiras tropicais.

Arquivo Brasileiro de Medicina Veterinária e Zootecnia, v.55. n.2. p.216-219. 2003.
MENEZES,L.A.S.; LEANDRO, W.M. Avaliação de espécies de coberturas do solo com potencial de uso em sistemas de plantio direto. Pesquisa Agropecuária Tropical, v.34, p.173-180, 2004.

MERTENS, D.R. Regulation of forage intake. In: FAHEY JUNIOR, G.C. (Ed). Forage quality, evaluation and utilization. Madison: American Society of Agronomy, 1994. p.450-493.

MOORE, J.E. Forage quality indices: development and applications. In: FAHEY JUNIOR, G.C. (Ed.). Forage quality, evaluation, and utilization. Madison, WI: Crop Science Society of America, 1994. p. 967-998.

NOGUEIRA, U.T ; MAURÍCIO, R.M.; GONÇALVES, L.C. Comparação de substratos com diferentes quantidades de carboidratos solúveis utilizando a técnica "in vitro" semi-automática de produção de gases. Arquivo Brasileiro de Medicina Veterinária e Zootecnia, v.58, n.5, p.901-909, 2006.

SILVA, D.B.; GUERRA, A.F; SILVA, A.C.; PÓVOA, J.S.R. Avaliação de genótipos de trigo mourisco na região do Cerrado. Brasília: Embrapa Cenargen, 2002, 20p. (Boletim de Pesquisa e Desenvolvimento, 21).

THEODOROU, M.K.; WILLIAMS, B.A.; DHANOA, M.S.; McALLAN, A.B.; FRANCE, J.A simple gas production method using a pressure transducer to determine the fermentation kinetics of ruminant feeds. Animal Feed Science and Technology, v.48, p.185-197, 1994. 
Rev. Bras. Saúde Prod. Anim., Salvador, v.17, n.4, p.599-607 out./dez., 2016 http://www.rbspa.ufba.br

VAN SOEST, P.J.; ROBERTSON, J.D.; LEWIS, B.A. Methods for dietary fiber, neutral detergent fiber, nonstarch polysaccharidesin relation to animal nutrition. Journal of Dairy Science, v.74, p.3583-3597, 1991.

WILLIAMS, B.A. Cumulative gas production techniques for forage evaluation. In: GIVENS, D.I.; OWEN, E.; AXFORD, R.F.E.; OMED, H.M. (Ed). Forage evaluation in ruminant nutrition. Wallingford: CAB International Publishing, 2000. p.189214.

Data de recebimento: 04/08/2015

Data de aprovação: 15/09/2016 